\title{
Prediction of outcome in severe head injury based on recognition of sleep related activity in the polygraphic electroencephalogram
}

\author{
B M Evans, J R Bartlett
}

\begin{abstract}
This study shows that the continuing presence of activity similar to normal sleep in the EEG in conjunction with the EEG polygraph (EEGP) can be used to determine the severity of brain damage after head injury. Recordings were taken within seven days of head injury from 154 unselected patients after resuscitation and emergency surgery. Sixteen patients with ongoing seizures were excluded. In the remaining 138 patients the presence of activity in the EEG, EEGP, or both, which can also be recognised in normal alertness and sleep, was noted. Particular attention was paid to the presence or absence of arousal related phasic activity involving EEG, motor, and autonomic changes. The traces were allocated to one of five groups: group 1, wakeful traces with normal alpha in at least one hemisphere; group 2, sleep-like traces with $\mathrm{K}$ complexes responsive to stimulation; group 3, traces with phasic activity related to abnormal spontaneous arousal including EEG changes; group 4, traces with abnormal spontaneous arousal activity without EEG changes; group 5, traces with no spontaneous arousal activity. The mean follow up was 21.5 months. Groups 2 and 3 were significantly associated with a good outcome and group 5 with death or a vegetative state. Comparison between the EEG/EEGP findings and the Glasgow coma scale at the time of the recording showed the EEG/EEGP to be the better predictor of outcome, particularly for individual patients.
\end{abstract}

(F Neurol Neurosurg Psychiatry 1995;59:17-25)

Keywords: head injury; outcome; sleep/wake mechanisms; EEG polygraph; Glasgow coma scale

Regional Department of Clinical

Neurophysiology

B M Evans

Department of

Neurosurgery, Brook

General Hospital,

Shooters Hill Road,

London SE18 4LW, UK

J R Bartlett

Correspondence to:

Dr B M Evans.

Received 4 August 1994

and in final revised form

and in final revised

Accepted 27 February 1995
At the onset of sleep there are well established changes from the wakeful alpha dominant EEG to the patterns of stages 1 to 4 sleep. ${ }^{13}$ More recently, spontaneous changes in the level of arousal have been shown both in normal sleep ${ }^{14-19}$ and in brain damage, ${ }^{18} 20-24$ which are related to the microstructure of sleep. These studies report spontaneous rhythmic changes in the arousal level of the EEG at intervals between seven and $60 \mathrm{sec}-$ onds that are associated with autonomic and motor changes. It has been suggested that these phasic changes are related to a physiological arousal cycle at sleep onset and that the same mechanism is responsible for the phasic activity seen in coma. ${ }^{182-24}$ There is evidence to support this concept from animal experiments concerning the arousal and sleep/wake mechanisms. ${ }^{25} 26$

This paper shows that physiological EEG/EEG polygraph (EEGP) activity related to sleep is recognisable in the damaged brain, correlates well with the severity of the damage after head injury, and can be used to predict outcome.

\section{Patients and methods}

Electroencephalograms, EEGPs, or both were obtained from 154 unselected patients (113 male, 41 female), admitted with head injury to the neurosurgical unit at The Brook General Hospital. Their ages ranged from 3 to 72 years (mean age $27 \cdot 1$ indicating a high proportion of younger patients). The clinical management included early resuscitation, often with an elective period of assisted ventilation using a muscle relaxant where necessary. High dose barbiturate treatment was not used. All electrophysiological traces were obtained within seven days of the injury and after resuscitation and emergency surgical procedures, using an SLE E8b or $100 \mathrm{~T}$ machine at the bedside with silver/silver chloride surface or platinum intradermal needle electrodes situated according to the modified Maudsley system of electrode placement. ${ }^{27}$ For the examples given in the figures, unless stated otherwise, silver/silver chloride disc electrodes were used, gain $50 \mu \mathrm{V} / \mathrm{cm}$; low frequency filters $0.5 \mathrm{~Hz}$; high frequency filters $70 \mathrm{~Hz}$. In 18 patients the EEG alone was recorded. In 63 patients polygraphic records were obtained which included an ECG recorded from the shoulders, a surface EMG from a suitable muscle, and respiration from a thermistor in the nostril or the expiratory valve of the ventilator. The ECGs were 


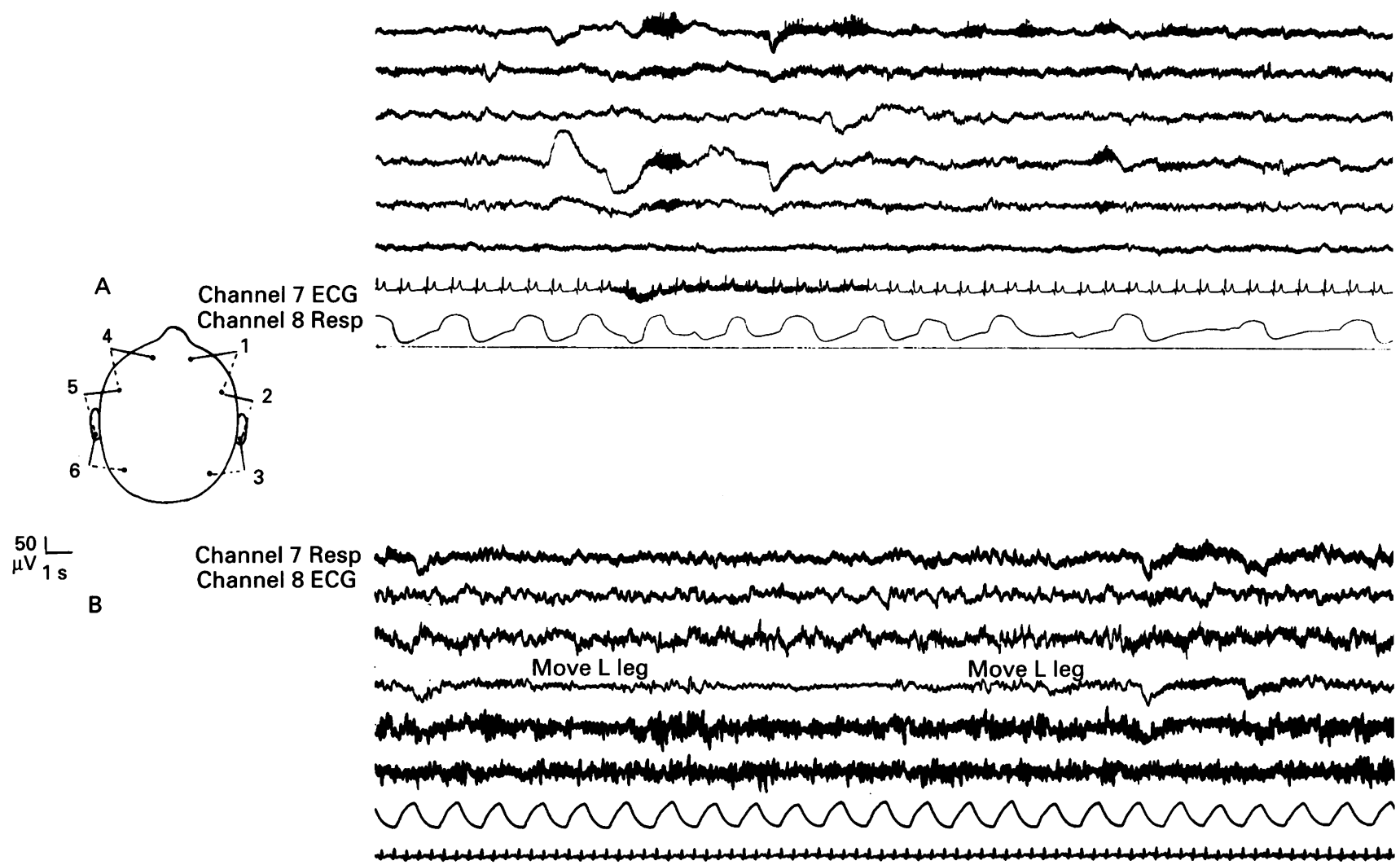

Figure 1 Group 1: wakeful trace. (A) Symmetric trace: a woman aged 41 was admitted to hospital after being thrown from a horse. She was drowsy and disorientated but able to answer questions (Glasgow coma scale grade 13). Clinical examination and CT were non-contributory. Lumbar puncture showed blood stained CSF. She made a rapid recovery. The EEGP, taken on the day after injury, shows well formed postcentral alpha and rolling eye movements typical of drowsiness. (B) Asymmetric trace. A man of 72 was admitted after being knocked down by a car. He was drowsy but able to speak and obey commands (Glasgow coma scale grade 13). He had a dense left hemiparesis including his face; CT showed a right frontal intracerebral haematoma that was evacuated on the day of admission. After operation he deteriorated and died two weeks later. The EEGP, taken three days after injury, shows a well formed alpha rhythm in the left hemisphere and slower waves at 3-7 Hz on the right. Note eye blinks in channels 1 and 4.

analysed by measuring the $\mathrm{R}$ wave interval to determine the beat to beat heart rate and plotting the results at one second intervals to produce a heart rate graph. In 73 patients the autonomic variables were obtained from a Hewlett Packard cardiorespiratory monitor (modification of a foetal heart rate monitor).

The recording methods were designed to provide an assessment of the physiological state of the patient coincident with the clinical assessment and were therefore not prolonged, lasting between 30 and 60 minutes. The traces were always observed during the recording by the same electroencephalographer (BME). Particular care was taken to ensure that the patient achieved the highest level of general arousal possible by stimulation of varying degrees of severity from calling the name to deep pain; the effects of this on the EEG polygraph were noted. Changes in the level of arousal, either spontaneous or after stimulation, were identified from the EEG and polygraph. Activity was considered to be related to arousal if it could be produced, altered, or when spontaneously present, reproduced, by stimulation given at the lower arousal levels. Clinical details, including the Glasgow coma score on a 14 point scale, ${ }^{9}$ were noted by the clinical team at the time of the record.

SEIZURE GROUP

Sixteen patients had continuous epileptiform activity, which made arousal changes impossi- ble to assess by EEG. These patients were excluded from further study.

The remaining 138 patients, without seizures, formed the study group. These were divided into five subgroups determined by the EEG and polygraphic findings. The principal criteria were the level of general arousal obtainable and the changes in arousal produced in any part of the EEG/EEGP, either spontaneously or after stimulation. When the EEG was asymmetric the findings from the more normal hemisphere were used for grouping.

\section{Group 1: wakeful records (fig 1)}

This group could be recognised from the EEG alone. There was a well formed and sustained postcentral alpha rhythm for at least part of the time over one or both hemispheres. The distribution and reactivity of the alpha and the presence of eye movements distinguished the findings from alpha coma.

The eye movements were characteristic, either blinking or rolling.

The polygraph did not contribute further useful information.

\section{Group 2: sleep-like records (fig 2)}

This group could be recognised from the EEG alone. The traces showed stage 2 sleep activity with $\mathrm{K}$ complexes, which could be reproduced by stimulation, on a background of low voltage theta $(4-7 \mathrm{~Hz})$ and delta $(<4$ $\mathrm{Hz}$ ). Records with only spindle activity or 
Figure 2 Group 2: sleeplike trace. $A$ boy aged 11 was unconscious from the time of injury. At the time of admission he had flexor arm movements, groaned, but did not open his eyes (Glasgow coma scale grade 6). His right pupil was fixed and constricted. He deteriorated after

admission, with fixed dilated pupils, bilateral extensor movements, and no vocalisation (Glasgow coma scale grade 4); $C T$ showed a film of extradural blood, without mass effect, for which surgery was not considered necessary. He was ventilated electively and made a good recovery within 48 hours with a transient left hemiparesis. The EEG on the day after injury (platinum needle electrodes) shows $a$ background of low voltage theta and delta with $K$ complexes following minimal stimulation (S) firstly by blowing on the skin and then by calling the name.

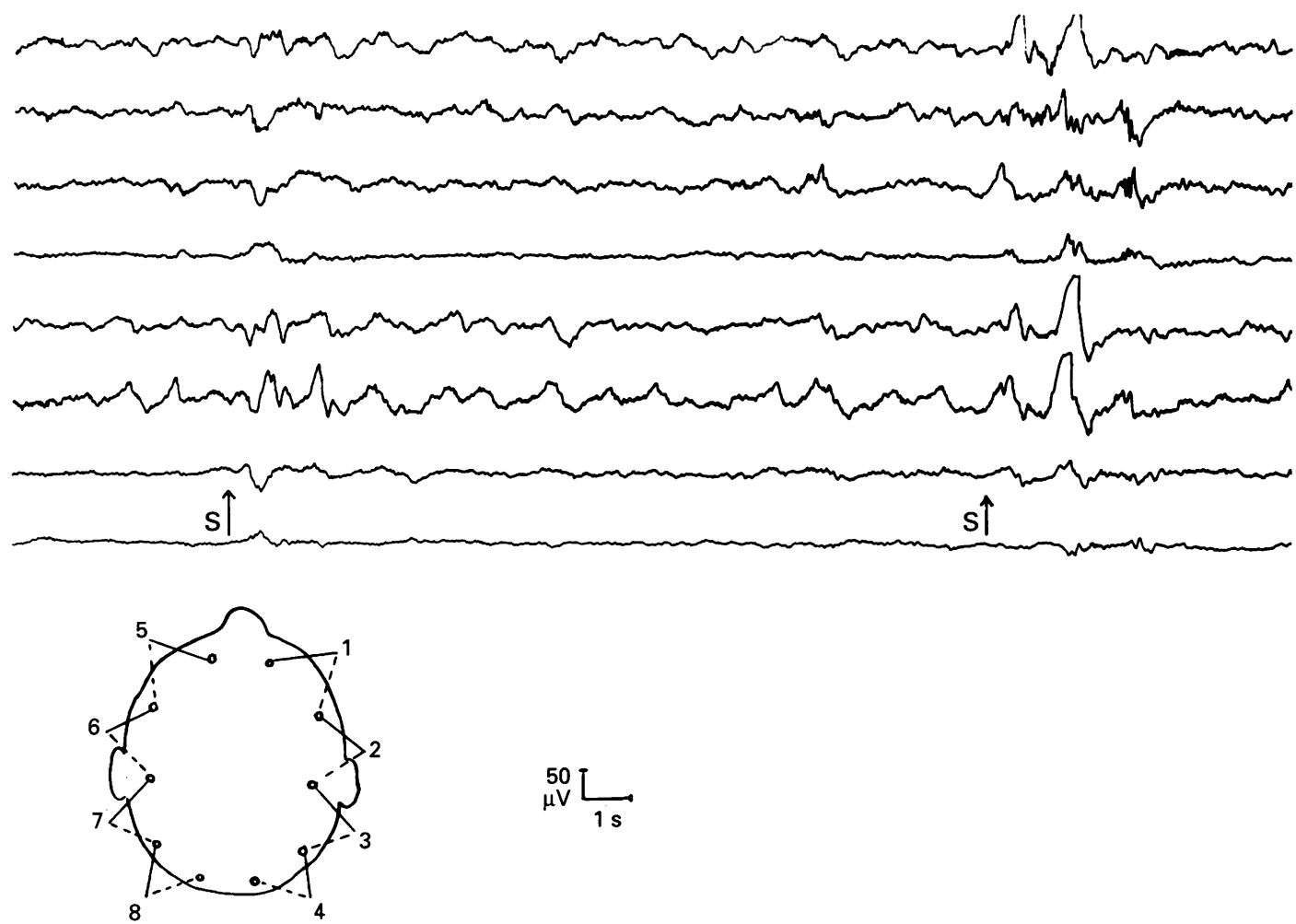

potentials resembling $\mathrm{K}$ complexes that were not sensitive to stimulation were not included.

Eye movements were present, unless pharmacologically paralysed, but were not contributory.

The polygraph added no useful information.

Group 3: abnormal spontaneous arousal activity with EEG change (fig 3A)

The characteristic findings were changes in the arousal level, both spontaneous and after stimulation. These involved all parts of the polygraph trace including the EEG.

Eye movements were present, unless pharmacologically paralysed, but were not contributory.

Polygraphic information was essential to distinguish this group from groups 4 and 5 . Changes in arousal were accompanied by increases in beat to beat heart rate, respiration rate, and muscle activity, which could be phasic or irregular, and were often exaggerated (fig 3A), with changes in heart beat of up to 100 beats/min within a few seconds.

Group 4: abnormal spontaneous arousal activity without EEG change (fig 3B)

The criteria for this group were the same as those for group 3 except that arousal changes were only present in the other parts of the polygraph and were not seen on the EEG.

Group 5: no spontaneous arousal activity (fig 4) This group showed no spontaneous arousal activity during the period of the recording (30-60 minutes). Changes on the EEG were never seen.
Spontaneous eye movements were absent even when the patient was not paralysed.

Changes in heart beat were not seen spontaneously (apart from respiratory sinus arrythmia) but stimulation sometimes produced a brief poorly sustained response in heart beat, EMG, or respiration (fig $4 \mathrm{~A}$ ).

Outcomes were obtained from the clinical notes; all patients were assessed at three months. Among the survivors, those in unremitted coma were classified as vegetative, those completely recovered were discharged, and those with any disability were followed up for varying times between six and 84 months. Outcomes were graded according to the criteria of Jennett and Bond ${ }^{28}$ as (1) good recoveries with no disability, (2) mild disability, (3) severe disability, (4) persistent vegetative state, (5) death. These groups were reduced to three: good 1 and 2, disabled 3, poor 4 and 5.

Statistical analysis of the relation between the clinical outcome and the EEG/EEGP groups was achieved by a $\chi^{2}(8 \mathrm{df})$ test.

\section{Results}

OUTCOMES

Table 1 shows the outcomes for the study group. Sixty six patients died within three months of their injuries. Follow up in the 72 survivors was between three and 84 (mean $21.5)$ months. There were $55(40 \%)$ good outcomes of whom 33 were back to normal and 23 were mildly disabled. Thirteen (9\%) were severely disabled. Seventy $(51 \%)$ poor outcomes comprised 66 deaths and four vegetative patients. 


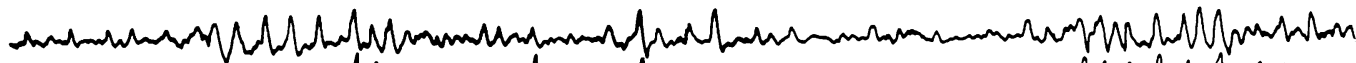

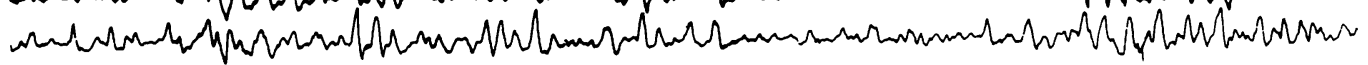

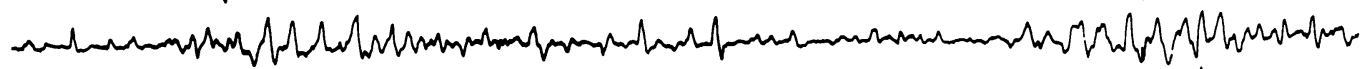

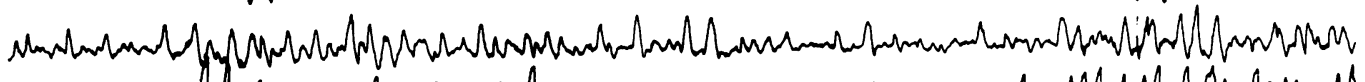

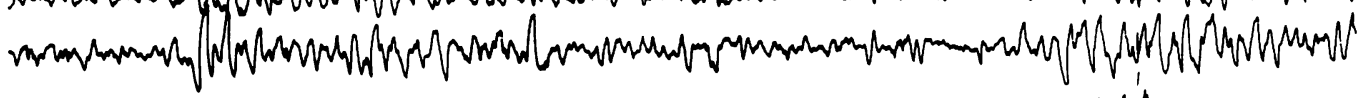

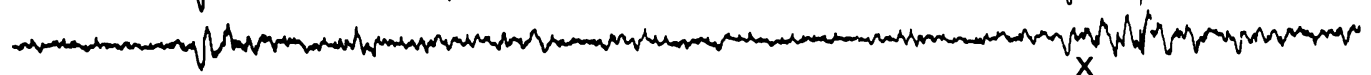

сы

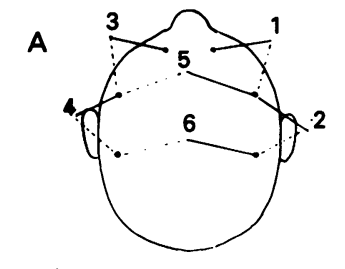

$50 \mu \mathrm{VL}$

1 s EEG

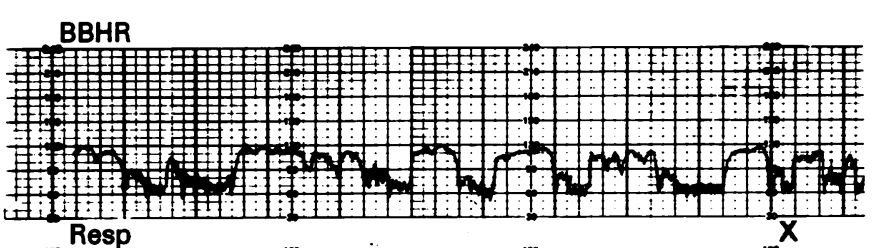

Resp

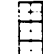

:

1 Min monitor

Figure 3 Group 3: abnormal spontaneous arousal activity. (A) With EEG change. A girl aged 16 was unconscious from the time of a road accident. Her pupils were equal and reactive. She responded to pain by flexion of the right and extension of the left arm. She made no sound but occasionally opened her eyes (Glasgow coma scale grade 7); CT showed some of the left arm. She made no electively ventilated for 48 hours. Her recovery was slow but after five months there was no residual deficit. EEGP was on the day after injury. Above: EEGP, channels 1-6 EEG, channel 8 ECG. Below:

cardiorespiratory monitor, respiration from ventilator expiratory valve (functioning poorly). The EEG shows bursts of high voltage slow waves both spontaneously and on painful stimulation. The monitor shows very pronounced and irregular beat to beat heart rate changes spontaneously and on stimulation ( $X$ on both traces). (B) Without EEG change. A man aged to beat heart rate changeling his motor cycle. On admission he was localising pain with his right arm, his eyes opened to pain, and he groaned occasionally (Glasgow coma scale grade 8). His right pupil was fixed and dilated and the left pupil reacted; CT showed biparietal and occipital fractures with left and right parietal and frontal and right temporal contusions; also a small right frontal intracerebral clot. He eventually made a good recovery with some memory impairment (last seen six years later). The traces were taken two days after injury. Above: EEGP, channels 1-8 EEG, channel 9 ECG. Below: cardiorespiratory monitor. The EEG showed no change when the patient was aroused spontaneously. The monitor shows periodic respiration with accompanying beat to beat heart rate changes occurring at about 30 second intervals; $X$ marks the spontaneous arousal movement on both traces. 


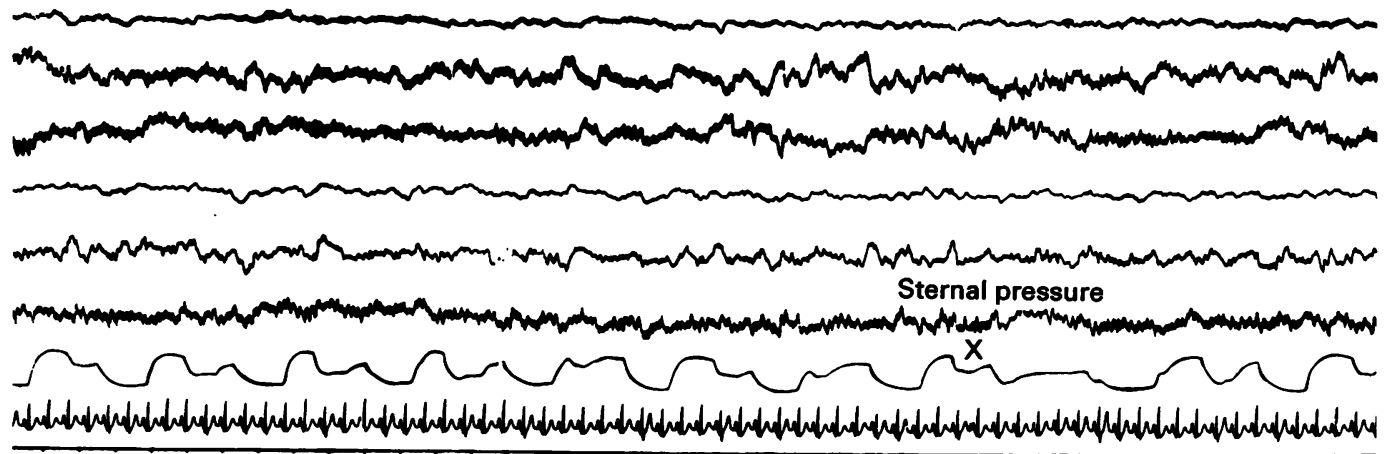

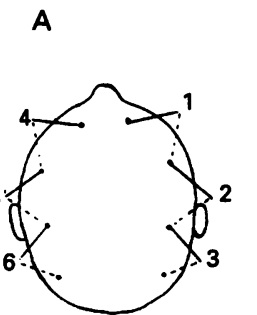

Channel 7 Resp Channel 8 ECG

$50 \mu \mathrm{VL}$
1 Min monitor

BBHR

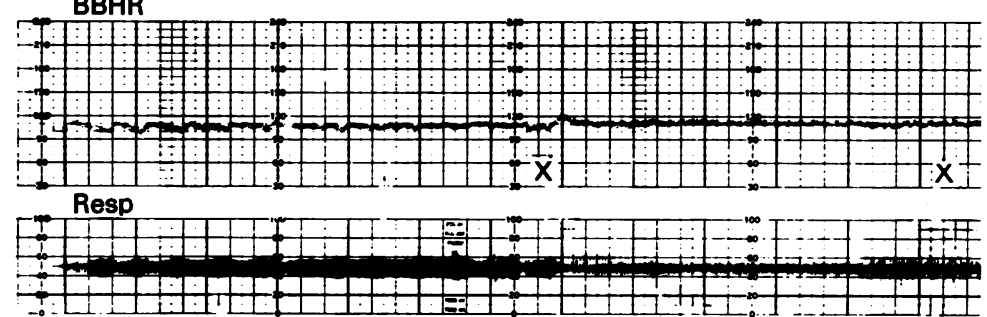

Figure 4 Group 4: no spontaneous arousal activity. (A) With EEG activity present. A man aged 44 fell off a ladder on to his head. On admission there was no movement in his legs but his arms extended; he was silent with closed eyes (Glasgow coma score grade 4). Both pupils were fixed and dilated. He was treated with dexamethasone and intravenous fluids; his arms then responded purposefully (Glasgow coma score grade 6) and his pupils became sluggishly reactive. A skull radiograph showed an occipital fracture. Over the next four days he deteriorated and died. Postmortem showed extensive contusion and petechiae throughout the hemispheres, cerebellum, and brain stem. Traces were obtained on the second day after injury. Above: EEGP, channels 1-6 EEG, channel 7 respiration, channel 8 ECG. Below: cardiorespiratory monitor. The EEG shows a mixture of frequencies from $2-7 \mathrm{~Hz}$ with no response to painful stimulus (sternal pressure). The monitor shows almost unvarying respiratory sinus arrythmia with minimal change to some stimuli, $X$ marks the moment of stimulation on both traces. (B) Without EEG activity. $A$ girl aged 12 was knocked down by $a$ car. On admission she flexed both arms. She was silent with closed eyes (Glasgow coma score grade 5). Her pupils reacted sluggishly to light; CT showed severe fractures of the lefi parietal and frontal bones with brain swelling, worse on the left and shift of the midline structures. She was electively ventilated and her wound explored. The skull fragments were mobile and there was necrotic extruded brain. She did not improve and died two days later. Traces were obtained on the day of injury, after surgery while the patient was artificially ventilated. Above: EEGP, channels 1-5 EEG. Below:

cardiorespiratory monitor. The EEG shows only some muscle and ECG artefact. The EEG and beat to beat heart rate did not respond to a painful stimulus (X). The heart beat trace shows only slight undulations, not related to respiration. 
Table 1 Outcome in the study of 138 seizure free patients compared with a multicentre study in $1976^{11}$

\begin{tabular}{llllll}
\hline & Died & $\begin{array}{l}\text { Persistent } \\
\text { vegetative state }\end{array}$ & $\begin{array}{l}\text { Severe } \\
\text { disability }\end{array}$ & $\begin{array}{l}\text { Mild } \\
\text { disability }\end{array}$ & Good \\
\hline EEGP & $66(48 \%)$ & $4(3 \%)$ & $13(9 \%)$ & $23(17 \%)$ & $32(23 \%)$ \\
1976 & $49 \%$ & $3 \%$ & $10 \%$ & $17 \%$ & $20 \%$ \\
\hline
\end{tabular}

Table 2 Glasgow coma scale in relation to the EEG/EEGP groups

\begin{tabular}{|c|c|c|c|c|}
\hline Scale & Wakeful & Sleep-like & $A S A \pm E E G$ & $N S A$ \\
\hline $\begin{array}{l}>8 \\
6,7,8 \\
<6\end{array}$ & $\begin{array}{l}8(89 \%) \\
1(11 \%) \\
0\end{array}$ & $\begin{array}{l}4(27 \%) \\
9(60 \%) \\
2(13 \%)\end{array}$ & $\begin{array}{r}6(10 \%) \\
34(59 \%) \\
18(31 \%)\end{array}$ & $\begin{array}{r}0 \\
7(12 \cdot 5 \%) \\
49(87 \cdot 5 \%)\end{array}$ \\
\hline
\end{tabular}

ASA $=$ abnormal spontaneous arousal $;$ NSA $=$ no spontaneous arousal

Table 3 Relation between the Glasgow coma scale and final outcome

\begin{tabular}{llrl}
\hline Outcome & $>8$ & $6,7,8$ & $<6$ \\
\hline Good & $10(55 \%)$ & $34(67 \%)$ & $11(16 \%)$ \\
Disabled & $2(11 \%)$ & $5(10 \%)$ & $6(9 \%)$ \\
Poor & $6(33 \%)$ & $12(23 \%)$ & $52(75 \%)$ \\
\hline
\end{tabular}

GLASGOW COMA SCALE SCORES

Table 2 shows the Glasgow coma scale scores for the study group: $>818(13 \%)$ patients. $6,7,851$ (31\%) patients, <6 69 (50\%) patients. Table 3 shows the relation of the Glasgow coma scale grades to outcome.

EEG/EEGP GROUPS

Group 1: wakeful records

There were nine $(6 \%)$ patients (two EEG, seven EEGP), average age 50 in this group (fig 1).

Six EEGs were asymmetric, five of which were among the patients with poor outcomes. Four of these patients had intracranial haematomas or haemorrhagic contusions, as did the one disabled patient.

The outcomes were: good three (33\%), disabled one (11\%), and poor five (55\%). The findings were of no predictive value (table 4 ).

All were in Glasgow coma scale grades 8 or higher (table 2 ).

Group 2: sleep-like records

The group contained 15 (11\%) patients (four EEG 11 EEGP), average age 15 (fig 2).

The outcomes were: good 14 (93\%), disabled one ( $7 \%$ ), poor none. This EEG pattern was strongly associated with a good recovery, (table 4).

Table 4 Relation between the five EEG/EEGP groups and final outcome (square brackets show predicted outcomes)

\begin{tabular}{|c|c|c|c|c|c|}
\hline \multirow[b]{2}{*}{ Outcome } & \multicolumn{5}{|l|}{ Group } \\
\hline & Wakeful & Sleep-like & $A S A+E E G$ & $A S A-E E G$ & $N S A$ \\
\hline Good & $\begin{array}{l}3(33 \%) \\
{[3.59]}\end{array}$ & $14(93 \%)$ & $33(75 \%)$ & $4(29 \%)$ & $1(2 \%)$ \\
\hline Disabled & $1(11 \%)$ & $1(7 \%)$ & $4(9 \%)$ & $2(14 \%)$ & $5(9 \%)$ \\
\hline Poor & $\begin{array}{l}5(55 \cdot 5 \%) \\
{[4 \cdot 56]}\end{array}$ & $\begin{array}{c}{[1 \cdot 41]} \\
0 \\
{[7 \cdot 61]}\end{array}$ & $\begin{array}{c}7(16 \%) \\
{[22 \cdot 31]}\end{array}$ & $\begin{array}{l}8(57 \%) \\
{[7 \cdot 10]}\end{array}$ & $\begin{array}{l}50(89 \%) \\
{[28 \cdot 4]}\end{array}$ \\
\hline
\end{tabular}

$\chi^{2}=80.52(8 \mathrm{df}), \mathrm{P}<0.001$

Good $=$ mild disability + normal; Poor $=$ died + vegetative; ASA $=$ abnormal spontaneous arousal; NSA = no spontaneous arousal.
There was a wide spread of Glasgow coma scale grades with two patients in grade 4 and three in grade 6 (table 2).

Group 3: abnormal spontaneous arousal activity with EEG change

There were $44(32 \%)$ patients (all EEGP), average age 23 (fig $3 \mathrm{~A}$ ).

The EEG activity varied from patient to patient. Higher arousal levels were accompanied by bursts of high voltage delta activity whereas the lower arousal periods contained either a mixture of theta and delta or delta of much lower amplitude. High levels of arousal were common and it was often necessary to wait for many minutes before seeing a period of low arousal. In many cases there was asymmetry of the delta which usually correlated with asymmetries in the clinical state.

The arousal episodes often occurred rhythmically with a periodicity of between 20 and 60 seconds but they could also be irregular (fig 3A). They could be brief or prolonged, sometimes lasting up to 10 to 15 minutes.

Outcomes in group 3 were: good 33 (75\%) patients, disabled four $(9 \%)$ patients, poor seven $(10 \%)$ patients. These findings were associated with a good recovery but less so than in the sleep-like group (table 4).

Group 4: abnormal spontaneous arousal activity without EEG change

This group contained 14 (10\%) patients, average age 24 years. All had EEGP (fig 3B). The EEG showed continuous delta activity, sometimes of low voltage, and often mixed with theta or alpha. Some patients showed spindles of beta (two of whom made good recoveries). The traces often showed asymmetry of the delta activity.

Arousal activity similar to that seen in group 3 was present in the polygraph traces other than the EEG, either rhythmic (fig 3B) or irregular.

The outcomes for this group were: good four $(29 \%)$, disabled two $(14 \%)$, poor eight $(57 \%)$. This finding was of no clear predictive value.

Groups 3 and 4 included most Glasgow coma score grades: $>8$ six patients $(10 \%), 8-6$ 34 patients $(59 \%),<6 \quad 18$ patients $(31 \%)$ (table 2).

Group 5: no spontaneous arousal activity

This group contained $56(41 \%)$ patients (five EEG, 54 EEGP), average age 27 (fig 4).

The EEG findings varied. Isoelectric records were seen in 23 patients. Continuous unvarying delta, often of low voltage, sometimes mixed with theta and alpha frequencies, and occasionally spindles of beta (not including the patient who recovered) were seen in 24 patients. Nine patients showed alpha coma.

The outcomes were good one $(2 \%)$, disabled five $(9 \%)$, poor $50(89 \%)$. This finding was strongly associated with a poor outcome (table 4).

Only the lower Glasgow coma score grades were represented in this group: $>80,8-6$ seven $(12 \cdot 5 \%),<649(87 \%)$ (table 2$)$. 
STATISTICAL RESULTS

Table 4 shows the results analysed by $\chi^{2}$ test $(8 \mathrm{df})$. The results were highly significant.

\section{Discussion}

This study shows that the physiological EEG/EEGP changes of normal sleep and wakefulness can be detected in head injury and can be used to provide information about the severity of the brain damage and hence predict the eventual outcome.

There is increasing evidence to suggest that the EEG/EEGP activity of sleep onset is concerned with the active change in behavioural state from wakefulness to delta sleep. The findings reported here suggest that sleep and waking may result from the operation of an intracerebral system, analogous to the pyramidal or visual systems, damage to which results in malfunction. The physiological mechanisms involved can still be identified in the damaged brain.

Of particular importance in this context is the experimental work on sleep spindles. ${ }^{25} 26$ In normal sleep, alternations between high and low arousal at intervals of seven to 60 seconds, associated with autonomic and motor changes are recognised. These are thought to relate to the microstructure of sleep as opposed to the macrostructure of the circadian and ultradian rhythms. ${ }^{14-19}$ Similar activity has long been recognised in the damaged brain with varying periodicities between 15 and 60 seconds. ${ }^{20-24}$ Many studies have linked this arousal related activity to changes in autonomic or cerebral autoregulatory mechanisms such as cerebral blood flow or CSF pressure. $14152129-31$ Although the phasic alternations in the damaged brain are not identical with those in normal sleep, particularly in respect to the type of EEG activity and the magnitude of the autonomic changes, there is little doubt that they are the same phenomenon..$^{1822}$ It is these phasic changes that relate to the abnormal spontaneous arousal activity described in groups 3 and 4.

The five EEG/EEGP trace types described show increasing levels of abnormality from wakefulness to absence of all arousal activity. The traces have been grouped in relation to the general level of arousal achievable, and the responsiveness of the EEG/EEGP to stimulation, rather than any particular EEG appearances. For this reason spindle activity alone, (Courjon's spindle coma ${ }^{1}$ ) was not used to categorise the sleep-like group (2) in the absence of reactive $K$ complexes.

The EEG/EEGP findings have been used to determine the neurophysiological state of patients at the time of the examination in a similar way to the clinical assessment provided by the Glasgow coma scale. The Glasgow coma scale is an effective method of assessing patients after head injury. ${ }^{9}$ These clinical tests record the type of motor response and level of awareness (the ability to relate appropriately to the surroundings) at maximum arousal. These are similar physio- logical functions to those shown by the EEG/EEGP, although the EEG/EEGP includes additional information about the quality of cortical function and the presence or absence of spontaneous arousal activity. To emulate the universal application of the Glasgow coma scale there was no attempt to select cases on the basis of injury type, age, or recent surgery.

The outcomes from the study group of 138 patients show the group to be of similar composition to that in the multicentre study undertaken in $1976^{11}$ (table 1). The Glasgow coma scale is known to provide one of the best correlations with outcome in head injury. ${ }^{11}{ }^{12}$ In some circumstances, however, it can be difficult to perform, particularly in patients being ventilated, with severe facial injuries, or with peripheral palsies or fractures. Therefore an additional method of assessment is of practical clinical importance. It is suggested that the EEG/EEGP provides such a method.

Table 3 shows the outcome of the study group in relation to the Glasgow coma scale. There is a correlation between the coma grades $<6$ and a poor outcome, the middle grades 8-6 show a mixed result with a preponderance of good outcomes. The highest coma grades did not correlate as well with a good outcome as other studies. ${ }^{10}$ Patients with high Glasgow coma scale grades were not usually admitted to the neurosurgical unit so that this finding probably reflects case selection by the admitting physicians. Some had a hemiparesis and were admitted to exclude a treatable cause for this, others had traumatic subarachnoid haemorrhage requiring investigation.

\section{EEG/EEGP GROUPS (TABLE 1)}

Group 1: the wakeful group

Despite a high level of awareness this group did not show a relation with good outcome. The asymmetries in the EEGs of six patients suggested that they had one severely damaged hemisphere and five had haematomata or haemorrhagic contusions. This finding probably reflects the case selection referred to and accounts for the poor outcome. The severity of damage to one hemisphere dictates the outcome here. As these patients were in Glasgow coma score grades 8 or above they represent some of the poor results among the higher Glasgow coma score grades shown in table 3 .

\section{Group 2: the sleep-like group}

These patients showed responsive EEG activity associated with normal stage 2 sleep. This group showed a strong positive correlation with good outcome. Patients did not always have high Glasgow coma score scores; two were in grade 4 and three in grade 6 . The excellent prospects for this group account for some of the patients with good outcomes among the lower Glasgow coma score grades (table 4). The relation of these EEG findings to good outcome has been shown several times before. ${ }^{27}$ 
Groups 3 and 4

Both of these groups showed abnormal spontaneous arousal activity. The EEG/EEGP showed spontaneous alternations in arousal level, which -could be duplicated by stimulation. There were associated, often exaggerated, autonomic and motor changes. The difference between groups 3 and 4 related solely to the presence or absence of EEG changes after arousal. These two groups could not be identified from the EEG alone. Some polygraphic information was essential, the most valuable being the beat to beat heart rate. The addition of the cardiorespiratory monitor was of great value in facilitating the distinction between the two abnormal spontaneous arousal groups ( 3 and 4 ) and group 5 (no spontaneous arousal). Groups 3 and 4 together had a similar outcome profile as the patients with Glasgow coma scale scores 6-8 (tables 2 and 3).

For group 3, the abnormal spontaneous arousal with EEG change is probably the same as the cycling EEG pattern that has been recognised for many years. ${ }^{352024}$ Group 3 was associated with a good outcome $(75 \%$ good) but less so than the sleep-like group.

For group 4 the arousal activity could only be recognised by autonomic or motor activity. Although the results were better than those of group 5 only four (29\%) patients made good recoveries. Group 4 contained some traces that may have been allied to the sleep-like activity of group 2; traces with beta spindles but no reactive $K$ complexes were excluded from group 2 and relegated to group 4 . This is the probable explanation for the two rapid and complete recoveries mentioned in the results section.

For group 5 there was no evidence of spontaneous arousal. Only one patient made a good recovery and the group is strongly associated with a poor outcome. The group included a high proportion of the patients with low Glasgow coma scale scores (table 3). Table 4 shows 11 (16\%) unexpectedly good recoveries in patients with Glasgow coma scale scores $<6$, a finding also recorded in other studies. ${ }^{910}$ The EEG/EEGP can identify surviving normal cerebral, autonomic, and motor activity, ${ }^{18}$ and thus provides a better prediction of outcome than the Glasgow coma scale alone.

The EEG findings in this group were varied. There were isoelectric records, records with continuous unvarying delta activity, and nine cases of alpha coma. Some mixture of frequencies was often present and several traces had spindles of fast activity, showing that this finding is not in itself a predictor of good outcome.

If the wakeful group (1) is excluded, the statistical studies show a steady deterioration of outcome across the other four groups, which reflects the increasing damage to cerebral function (table 4).

The relation of poor outcome to increasing age in head injury is well established ${ }^{10-12}$ and the EEG/EEGP groups described have differing age profiles. Whereas groups 3 and 4 (abnormal spontaneous arousal with and without EEG changes) and group 5 (no spontaneous arousal) were similar to the mean ages of the study group as a whole group 1 (wakeful) had a much higher average age (50 years). It is possible that older brains respond to injury differently from younger ones, possibly as a result of primary or secondary vascular changes such as infarction of haemorrhage. This is supported by the finding of six unilateral hemispheric lesions among these patients. Group 2 (sleep-like) had a much lower average age ( 15 years) than the study group as a whole. The EEG appearances here were those of normal sleep implying no serious degree of cerebral harm. A possible explanation for this finding may be a greater susceptibility in younger patients to reversible brain stem shock, which has been postulated by some workers. ${ }^{32}$

The findings show the value of the EEG/EEGP in the evaluation of patients with head injury, both in its own right and to provide supplementary information when the Glasgow coma score is difficult to use. The EEG/EEGP gives a better picture than the Glasgow coma score of the functional state of the neuraxis in individual patients.

We thank Professor B Everitt for statistical advice.

1 Courjon J. La Place de l'electroencephalographie en traumatology cranienne. Cahiers Medicaux Lyonnais 1962;38: 315-7.

2 Chatrian GE, White LE, Daly D. Electroencephalographic patterns resembling those of sleep in certain comatose states after injuries to the head. Electroencephalogr Clin Neurophysiol 1963;15:272-9.

3 Bergamasco B, Bergamini L, Doriguzzi T, Fabiani D. Clinical value of the sleep electroencephalographic patterns in post-traumatic coma. Acta Neurol Scand 1968; terns in post-

4 Bricolo A, Turazzi S, Faccioli F. Combined clinical and EEG examinations for assessment of severity of acute head injuries. Acta Neurochir Suppl (Wein) 1979;28: 35-9.

5 Bricolo A, Turella G. Electroencephalographic patterns of acute traumatic coma: diagnostic and prognostic value. f Neurosurg Sci 1973;17:278-85.

6 Rumpl E, Prugger M, Bauer G, Gerstenbrand F, Hack $\mathrm{JM}$, Pallua $\mathrm{A}$. Incidence and prognostic value of spindles in post-traumatic coma. Electroencephalogr Clin Neurophysiol 1983:56:420-9.

7 Dusser A, Navelet D, Devictor D, Landrieu P. Short and long term value of the electroencephalogram in children long term value of the electroencephalogram in children
with severe head injury. Electroencephalogr Clin with severe head injury.

8 Rae-Grant AD, Barbour PJ, Reed J. Development of a novel EEG rating system for head injury using dichotomous variables. Electroencephalogr Clin Neurophysiol 1991;79:349-57.

9 Teasdale G, Jennett B. Assessment of coma and impaired consciousness, a practical scale. Lancet 1974;ii:81-3.

10 Jennett B, Teasdale G, Brackman R. Predicting outcome in individual patients after severe head injury. Lancet 1976; i: 1031-4.

11 Jennett B, Teasdale G, Galbraith S. Severe head injuries in three countries. F Neurol Neurosurg Psychiatry 1977; 40:291-8.

12 Jennett B, Teasdale G. Prognosis after severe head injury. In: Jennett B, Graham D, eds. Management of head injuries. Philadelphia PA: Davis, 1981:317-32.

13 inuries. Philadelphia PA. Davis, the cerebral cortex during sleep. Science 1938;81: the cere

14 Coccagna G, Mantovani M, Brignani F, Manzine A, Lugaresi E. Arterial pressure changes during spontaneous sleep in man. Electroencephalogr Clin Neurophysiol neous sleep in man

15 Lugaresi E, Coccagna G, Mantovani M and Lebrun R. Some periodic phenomena arising during drowsiness and sleep in man. Electroencephalogr Clin Neurophysiol 1971;32:701-5.

16 Terzano MG, Mancia D, Salati MR, Costani A, Decembrino A, Parrino L. The cyclic alternating pattern as a physiologic component of normal sleep. Sleep 1985;8:137-45.

17 Terzano MG, Parrino L, Spaggiavi MC. The cyclic 
alternating pattern in the dynamic organisation of sleep Electroencephalogr Clin Neurophysiol 1988;69:437-47.

18 Evans BM. Periodic activity in cerebral arousal mechanisms - the relationship to sleep and brain damage. Electroencephalogr Clin Neurophysiol 1992;83:130-7.

19 Evans BM. Cyclical activity in non-rapid eye movement sleep: A proposed arousal inhibitory mechanism. Electroencephalogr Clin Neurophysiol 1993;86:123-31.

20 Fischgold F, Matthis P. Obnubilations, comas et stupeurs. Electroencephalogr Clin Neurophysiol 1959;11:(suppl 11).

21 Cooper R, Hulme A. Changes of the EEG and other variables during sleep in patients with intracranial variables during sleep in patients with intracranial
lesions. Electroencephalogr Clin Neurophysiol 1969;27: lesions.

22 Evans BM. Cyclic EEG changes in subacute spongiform and anoxic encephalopathy. Electroencephalogr Clin Neurophysiol 1975;39:587-9.

23 Evans BM. Patterns of arousal in comatose patients. f Neurol Neurosurg Psychiatry 1976;39:392-402.

24 Terzano MG, Gatti PL, Manzoni GC, Formentini E, Mancia $\mathrm{D}$. Is the EEG cyclic alternating pattern an autonomous entity? Analytic study in a case of post traumatic coma with a good prognosis. Eur Neurol 1982; 21:324-34.

25 Steriade $M$. Brain electrical activity and sensory processing during waking and sleeping states. In: MH Kryger, T
Roth and WC Dement, eds. Principals and practice of sleep medicine. New York: Saunders/Harcourt Brace Jovanovic 1989:86-104.

26 Steriade $M$, Gloor $\mathrm{P}$, Llinas $\mathrm{RR}$, Lopes da Silva $\mathrm{FH}$, Mesulam M-M. Basic mechanisms of cerebral thythms. Electroencephalogr Clin Neurophysiol 1990;76:481-508.

27 Pampiglione G. Some anatomical considerations upon electrode placement in routine EEG. Proceedings of the Electrophysiological Technologists Association 1957;7: 20-30.

28 Jennett B, Bond M. Assessment of outcome after severe brain damage. A practical scale. Lancet $1977 ; \mathrm{i}: 480-4$.

29 Lundberg N. Continuous recording and control of ventricular pressure in neurosurgical practice. Acta Psychiat Scand 1960;36:(suppl 149)

30 Munari C, Calbucci F. Correlations between intracranial pressure and EEG in coma and sleep. Electroenceph Clin Neurophysiol 1981;51:170-6.

31 Newell DW, Aaslid R, Stroos R, Reulen HJ. The relationship of blood flow velocity fluctuations to intracranial pressure B waves. F Neurosurg 1991;76:415-21.

32 Plum F, Saper CB. Abnormal physiology in relation to arousal, newer concepts of autonomic projections. In: Villani $R$, Papo I, Giovanelli $M$, Gaini SM and Tome G. Exerpta Medica, 1983:67-73.

\section{NEUROLOGICAL STAMP}

\section{Coca shrub (Erythroxylum coca)}

The main alkaloid found in the coca leaves is cocaine. For centuries the Indians of Peru and Bolivia chewed the leaves for their stimulating effects. In the middle of the 19th century the linguist $\mathrm{J} \mathrm{J}$ Von Tschudi became interested in the leaves for increasing physical performance. In Paris a manufacturer named Mariani made wine from coca leaves and marketed it as a tonic. This became very popular in Europe and the United States. Enthusiasts included President William McKinley, Thomas Edison, and the Tsar of Russia and Mariani received a medal of appreciation from the Pope, At various times attempts were made to use coca as a treatment for syphilis and whooping cough but without obvious success. In 1859 the Austrian explorer and ship's doctor Karl Von Scherzer brought dried coca leaves to Europe and gave them to the German chemist Wöhler of Göttingen for analysis. In 1859 Wöhler's pupil Niemann succeeded in extracting the effective component of the leaves, which he called cocaine. Moreno Y Maiz, a Peruvian doctor, wrote, in 1868, of cocaine's ability to abolish sensation. He posed the question as to whether cocaine could be used as a local anaesthetic.

In 1884, after using it to treat his own depression, Sigmund Freud introduced cocaine to the physicians of Vienna. He maintained that it was valuable for that disorder, for eliminating nervous stomach complaints, and for augmenting mental and physical efficiency. He also commented on its ability to render mucous membranes insensitive. Freud attempted to cure a variety of nervous diseases with cocaine, even hydrophobia, but failed. In 1885 his treatment of a patient with trigeminal neuralgia by injection of cocaine was unsuccessful. In all probability he missed the nerve.

In 1884, Dr Carl Koller, a colleague of Freud, discovered that the human eye could be rendered insensitive to pain with cocaine, so heralding the start of local anaesthesia. Other men took up and advanced the idea of local anaesthesia, bringing cocaine out of the restricted field of ophthalmology. Halstead injected cocaine into the inferior alveolar nerve; a discovery that revolutionised dentistry. Halstead later became addicted to the drug; he treated his addiction with morphine and became a mor-

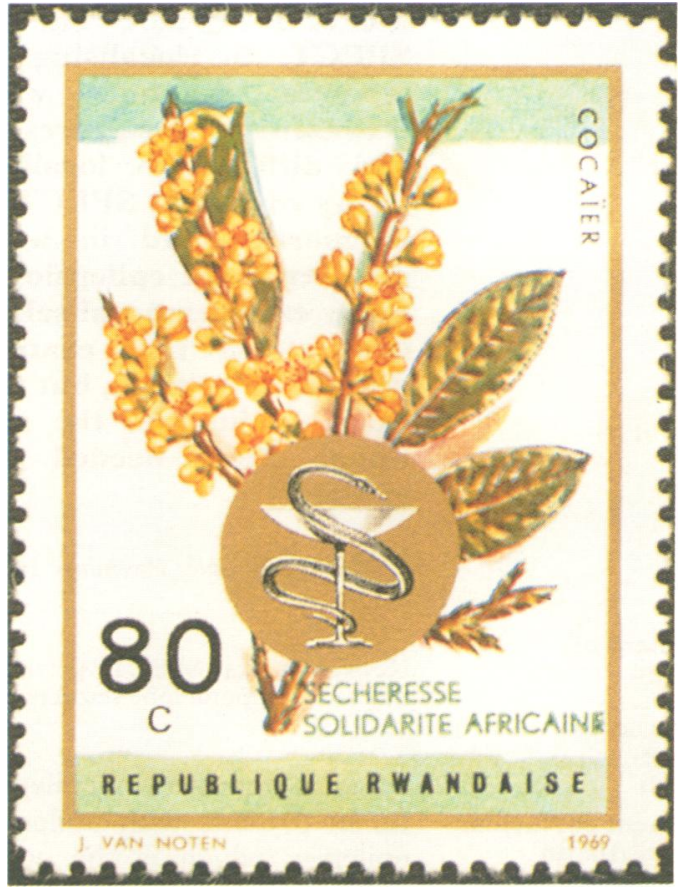

phine addict. Earlier, in a reverse approach, Freud had treated his friend Ernst Fleishl's morphine addiction with cocaine and converted him into a cocaine addict. Sir Arthur Conan Doyle had his fictional detective, Sherlock Holmes, take cocaine to keep his wits occupied when not working on a case.

In 1886 John Pemberton of Atlanta, Georgia, introduced Coca Cola, originally an elixir from the cola leaves and caffeine rich extracts from the cola nut. He promoted it as a headache remedy and stimulant. Cocaine was removed from the formula in 1906.

Local anaesthetics such as lignocaine, benzocaine, and procaine have cocaine's anaesthetic properties without its stimulatory side effects.

The coca shrub was shown on a stamp issued by Rwanda in 1969 (Stanley Gibbons 311, Scott 301). L F HAAS 